\title{
Promising Measures to Reduce the Harmful Effects of Man-made Waste from Ferroalloy Production
}

\section{Vladimir Ivanovich Zhuchkov¹, Leopold Igorevich Leontyev², and Oleg Vadimovich Zayakin ${ }^{1}$}

${ }^{1}$ Institute of Metallurgy of the Ural Branch of the Russian Academy of Science, Yekaterinburg, Russia

${ }^{2}$ Presidium of the Russian Academy of Sciences, Moscow, Russia

\section{Abstract}

This article formulates a list of promising measures to reduce the harmful impact of man-made waste from ferroalloy enterprises on the environment: (1) technical measures: replacement of the main and auxiliary obsolete equipment with new environmentally safe, allowing to significantly reduce or completely eliminate hazardous emissions and the formation of unclaimed production waste; (2) introduction of energy-saving

Corresponding Author: Oleg Vadimovich Zayakin zferro@mail.ru

Received: 5 February 2019 Accepted: 6 March 2019 Published: 17 March 2019

Publishing services provided by Knowledge E

(c) Vladimir Ivanovich Zhuchkov et al. This article is distributed under the terms of the Commons Attribution License, which permits unrestricted use and redistribution provided that the original author and source are credited.

Selection and Peer-review under the responsibility of the NIOKR-2018 Conference Committee. technologies: the use of physical and chemical energy of top gas from ore-reduction furnaces in turbine generators and in the contrivance for preheating and partial reduction of charge materials elements, etc.; (3) prevention and localization of emissions due to the modernization of existing equipment: sealing and shelter of the main melting equipment, places of loading and unloading of bulk materials, prevention of dusting for the ore materials warehouses, tailing ponds, sludge collectors, etc.; (4) cleaning of harmful emissions, the formation of which cannot be prevented; (5) introduction of innovative waste-free and low-waste technologies with the integrated use of raw materials: utilization of accumulated and current waste (slags, sludge, etc.) that form during the production of ferroalloys, reducing or completely eliminating the waste dumps and sludge collectors; (5) deeper ore preparation with the exception of the use of toxic reagents; and (6) more complete and economical use of water, the creation of closed water systems, the use of modern highly efficient treatment facilities, etc.

Keywords: metallurgy, ferroalloys, man-made wastes, slag, sludge

In modern society, the scale of consumption for natural resources is constantly increasing and, accordingly, the amount of emissions for various wastes into the environment increases, significant changes occur in natural ecological processes and an imbalance in their flow. On this basis, the problems of nature protection and the rational use of natural resources in the Russian Federation are among the most important state tasks.

To a large extent, this also applies to ferroalloy production.

\section{G OPEN ACCESS}


The main measures to reduce the harmful effects of ferroalloy enterprises on the environment $[1,2]$ include the following.

1. Technical measures: replacing the main and auxiliary obsolete equipment with a new environmentally safe, allowing to significantly reduce or completely eliminate hazardous emissions and the formation of unclaimed production waste.

2. The introduction of energy-saving technologies: the use of physical and chemical energy for the top gas of ore-reduction furnaces in turbine generators and in contrivance for preheating and partial restoration of charge material elements, etc.

3. Prevention and localization of emissions due to the modernization of existing equipment: sealing and shelter of the main smelting equipment, places of loading and unloading of bulk materials, prevention of dusting for the ore materials warehouses, tailing ponds, sludge collectors, etc.

4. Purification of harmful emissions, the formation of which cannot be prevented.

5. The introduction of innovative waste-free and low-waste technologies with the integrated use of raw materials: utilization of accumulated and current waste (slags, sludge, etc.) generated during the production of ferroalloys, with the reduction or complete elimination of this waste dumps and sludge collectors; deeper ore preparation with the exception for the use of toxic reagents; more complete and economical use of water, the creation of closed water systems, the use of modern highly efficient treatment facilities, etc.

In the field of ferroalloy production, the already tense ecological situation is significantly complicated by the need to use low-quality (poor, with a high content of harmful impurities) mineral raw materials, which leads to a decrease in technical and economic indicators for producing ferroalloys, and primarily leads to decrease of the extraction degree for the main component in the alloy. The low degree of use for the valuable elements of the alloys is associated with their losses during the extraction, ore preparation, at the stage of ferroalloys production and during the smelting of steel. The losses of such elements as manganese or chromium at the extraction stage average 5-10\%, at the ore preparation stage $-27-30 \%$, production of ferroalloys $-12-40 \%$, while steelmaking - 5-30\%. As a consequence, the share of end-to-end extraction of manganese and chromium into finished products does not exceed $30-40 \%$ of that extracted from the subsoil [3]. 


\section{Technical activities}

The main park of smelting units of the Russian Federation for the production of ferroalloys is considerably obsolete. For the production of large-tonnage ferroalloys, AC ore-reduction electric furnaces and blast furnaces are mainly used. The use of this equipment does not allow to fully process the fine fraction charge materials and requires the introduction of an additional process stage - agglomeration, which, in addition to the loss of the main elements, increases energy consumption and leads to an increase in the prime cost of the final product. The installation of DC (direct-current) electric furnaces solves the problem of using small fractions not only of ore raw materials, but also fine man-made industrial wastes. A good example of complex processing for poor chromium ore raw materials is equipment and technology implemented in South Africa [4], where platinum group metals are initially extracted from chrome ores, and the remaining fine fraction concentrate (less than $1 \mathrm{~mm}$ ) after ore preparation is sent to DC-based reduction furnaces. Several years ago, four direct-current ore-reduction furnaces with a transformer capacity of 72 MVA [5] were successfully placed into service at Aktobe Ferroalloy Plant JSC (Kazakhstan, Aktobe). This technology makes it possible to exclude operations on the agglomeration of charge materials from the process chain (which may be 15 to $40 \%$ in the prime cost of ferrochrome), return small fractioned man-made waste of its own production to the technological redistribution and significantly improve the environmental situation at both mining and metallurgical enterprises.

Promising are the designs of electric furnaces, which allow separately or fully to discharge from the furnace either slag or metal, leaving the desired melt for further processing. This will significantly expand the capabilities of technologists, create conditions for the sequential selective reduction and separation of elements, metal refining.

\section{The introduction of energy-saving technologies}

Exhaust gases of ore-smelting furnaces contain about $70 \%$ of $\mathrm{CO}$, which is not used in modern conditions of domestic ferroalloy enterprises (it is being burned, ejected). At foreign enterprises, waste gases are widely used for drying, heating, and pre-reduction of charge materials supplied to ore-reduction furnaces. Large industrial studies on the heating and selective reduction of elements of the poor chromium ores of the Kemi deposit were carried out by Outokumpu in Finland. According to the data of Daavittila J. (Outotec Oyj, Finland), it is shown the possibility of solid-phase chromium reduction up to $80-90 \%$ in a rotary kiln, as well as selective reduction of iron (over $80 \%$ ) and chromium 
(10\%) in the agglomerated mass when using exhaust gases of the ore-reduction electric furnaces. This scheme allows to use both physical and chemical energy of the top gas. The heating of charge materials with top gases [6] located in baskets above ore reduction furnaces (Outotec, Tornio, Finland) was successfully introduced into the production process. In [7], the principal possibility and feasibility of installing a gas turbine for generating electricity, which can improve the energy balance and profitability of an enterprise, is shown.

\section{Prevention, localization, and clearance of harmful emissions}

The main obstacle to the use of ferroalloy top gas is the use of ore reduction furnaces of open or semi-closed type at Russian ferroalloy enterprises, which leads to the dilution of gases with air and a decrease in their value as a fuel. This does not happen when the furnaces are closed with a roof or sealed. For dust collection, open and semiclosed furnaces can be equipped with dry-type gas cleaners when the temperature of the exhaust gases decreases by diluting them with air. But the dry system for gas cleaning does not allow to catch dangerous microcomponents $\left(\mathrm{SO}_{X}, \mathrm{NO}_{X}, \mathrm{H}_{2} \mathrm{~S}\right.$ and others) [3]. When using closed and leak-free ore-reduction furnaces, as a rule, a wet gas cleaning system is used, that has scrubbers and Venturi tubes in its composition. Wet gas cleaning system has advantages over dry in a number of parameters, such as the degree of purification of waste gases (99.96-99.99\%), as well as the possibility of trapping a number of microcomponents, both solid and gaseous (by dissolving in water or captured by it). However, the transition to closed furnaces under existing ferroalloy production technologies in most cases is accompanied by a decrease in the extraction of the main elements in the alloy, a decrease in the productivity of the smelting units, and for some types of ferroalloys, it is generally impossible to conduct the process in sealed furnaces. The introduction of sealed electric furnaces requires research and development and the creation of new technological schemes of production. This will not only significantly reduce the amount of dust emissions into the atmosphere, but also increase the output of high-caloric top gas.

\section{The introduction of innovative waste-free and low-waste technologies with the integrated use of raw materials}

During the production of ferroalloys, a large amount of by-products is formed: slags, dusts and gas treatment sludge. The main amount of produced ferroalloys and formed 
waste (over $90 \%$ ) is accounted for by manganese, chromium and silicon alloys. Recycling of metallurgical wastes, including ferroalloy, production solves several problems at once - eliminates or reduces the harmful effects of technogenic sediments on the air or water basin; returns the necessary raw materials to the main production; reduces the prime cost of the main product through the use of secondary raw materials; allows to adjust the production of various new products from man-made waste [8, 9]. The main wastes of ferroalloy production are slags, annual volumes of their formation in the Russian Federation are estimated at more than 800 thousand tons / year [3]. Ferroalloy slags, as a rule, are an oxide material with metal beads entangled in it. The situation is aggravated by the fact that these beads, unlike metal beads in steelmaking, often cannot be separated from the slag mass by magnetic separation methods due to weak magnetic properties, which require the use of more complex methods and aggregates. In [10], the possibility of using the $\mathrm{X}$-ray radiometric method of slag separation for the aluminothermic production of the Klyuchevsky Ferroalloy Plant was described. Ukrainian scientists, metallurgists for the recycling of waste from the ferromanganese production proposed to use the method of pneumoseparation [11]

Standard application areas of slags from chromium and manganese ferroalloys [12] after separation of the metal concentrate are construction and agriculture (crushed stone for road filling, filler in concrete [13], soil liming), but at the same time, as shown in several works [14, 15], the presence of such components in the composition of slag as $\mathrm{Cr}^{6+}, \mathrm{MnO}$, remains unfavorable both for plants, animals, and for people.

A special feature of slags for obtaining high-carbon ferrochromium is their "refractoriness", which allows to suggest ways of their alternative use in the refractory industry during the production of bricks and tap hole mixes for their own needs of a ferroalloy plant $[16,17]$.

The main disadvantages of slags for the refined grades of ferroalloys are their tendency to self-disperse into fine powder, which makes it impossible to process them into construction macadam [18]. A large number of works have been devoted to studying the properties of decayed highly basic slags and their practical use. It has been proposed to use them for the production of cold asphalt concrete and clinker, glass [19] and a lime substitute for neutralizing soil and sparge water [20], for preparing household chemicals and other purposes. However, it is well known that in ferroalloy plants not all the metal entangled in the slag is recovered and not all the disintegrated slag is used in industry or agriculture, but it accumulates in millions of tons in dumps, representing a serious environmental hazard. A number of research papers are devoted to solving the problem of stabilizing these slags [21-25]. 
As the analysis shows, specialists from various fields of science, metallurgists, chemists, refractories, builders, farmers, etc. deal with the problems of reducing the amount of waste produced in ferroalloy production and processing. However, until today there is no single effective method for technical-economic assessment of man-made waste from ferroalloy production.

\section{Funding}

This work was supported by the Russian Foundation for Basic Research (Project No. 18-29-24027).

\section{References}

[1] Lisin V.S., Yusfin Yu.S. (1998). Resource and environmental problems of the XXI century and metallurgy. Moscow: High School

[2] Zhuchkov V.I., Zayakin O.V. (2010). Environmentally protective measures in ferroalloy production. Rasplavy, no 4, pp. 66-69.

[3] Zhdanov A.V., Zhuchkov V.I., Dashevskiy V.Ya., et al. (2014). The use of ferroalloy production waste. Stal', no. 3, pp. 92-98.

[4] Beukes J. P., Dawson N. F., Van Zyl P.G. (2010). Theoretical and practical aspects of $\mathrm{Cr}(\mathrm{VI})$ in the South African ferrochrome industry. Proceedings of the Twelfth International Ferroalloys Congress. Sustainable Future. Helsinki, Finland.

[5] Privalov O., Abdulabekov Ye., Nurmukhanbetov Zh., et.al. (2013). Adjustment of idgh carbon ferrochrome composition in DC furnaces. Proceedings of Thirteenth International ferroalloys congress. Almaty, Kazakhstan: Infacon - XIII.

[6] Lyakishev N.P., Gasik M.I. (1999) Chromium metallurgy. Moscow: ELIZ.

[7] Yaroshenko Yu.G., Gordon Ya.M., Hodorovskaya I.Yu. (2012). Energy effective and resource -saving technologies of ferrous metallurgy. Yekaterinburg: UIPC.

[8] Kastcheev I.D., Zemlyanoy K.G., Dosekenov M.S. et al. (2012). The main characteristics of slags and dust formed during the production of ferrochrome. Proceedings of the int. congress "Fundamental basis of technologies for processing and recycling of man-made waste". Ekaterinburg: "UIPC"

[9] Matsumoto, T., Tobo H., Watanabe K. (2017). Ironmaking and steelmaking slag products and its new effective utilization technology JFE Giho, no. 40, p. 1-6.

[10] Perepelicin V.A., Rytvin V.M., Gilvarg S.I. et al. (2014). Aluminothermic ferroalloys slags. Ekaterinburg: Uralskiy rabochiy. 
[11] Velichko B.F., Gasik M.I., Koval A. V. (1991). Complex technology for the disposal of waste slags, dusts and sludges formed during the smelting of manganese alloys and electrofused. Steel, no. 10, pp. 74-78.

[12] Yaroshenko Yu.G., Gordon Ya.M., Hodorovskaya I.Yu. (2012). Energy effective and resource saving ferrous metallurgy technologies. Ekaterinburg: UIPC.

[13] Ochiai T., Inoue Y., Tanimoto F. et al. (2017). Application of "Ferroform" to concrete pavement. JFE Giho, no. 40, pp. 51-56.

[14] Midander K., Frutos A. De, Hedberg Y. et al. (2010). Bioaccessibility of ferrochromium and ferro-silicon-chromium particles compared to pure metals and stainless steel - aspects of human exposure. Proceedings of the Twelfth International Ferroalloys Congress. Sustainable Future. Helsinki, Finland.

[15] Stockmann-Juvala H., Zitting A., Wailinder I., et al. (2010). Use of read-across in the health risk assessment of ferrochromium alloys under REACH. Proceedings of the Twelfth International Ferroalloys Congress. Sustainable Future. Helsinki, Finland.

[16] Kascheev I.D., Dosekenov M.S., Zemlyanoy K.G., et. al. (2012). Recycling of technogenic wastes from the production of high-carbon ferrochrome for refractory materials. Journal of International Scientific Publications «Materials, Methods \& Technologies», vol. 6, part 3, pp. 154-164.

[17] Dosekenow M.S., Zhuchkov V.I., Izbembetov D.D., et al. (2012). Formation and use of the man-made wastes in ferroalloys production. Proceedings of the int. congress "Fundamental basis of technologies for processing and recycling of man-made waste". Ekaterinburg: LLC “UIPC”.

[18] Fadeev V.I., Ostrovskiy Ya.I., Veselovskiy I.A. et al. (2009). Processing of chromic slags in the conditions of OJSC "SZF. Proceedings of the All-Russian Conf. with elements of a school for young scientists. Ekaterinburg: Ural Center for Academic Services.

[19] Guloyan Yu.A., Smirnov V.F., Katkova K.S. et al. (1973). Improving the efficiency of the production of painted bottles using ferrochromium slags. Abstracts. meeting "Improving the efficiency of technological processes in the production of glassware.". Moscow.

[20] Vasilieva S.N., Menajieva R.A., Shirokov A.F. (1973). The effectiveness of liming for the acidic soils of the Tyumen region by metallurgical slags. Slags of ferrous metallurgy. Proceedings UraINIIChM.

[21] Akberdin A.A., Kim A.S., Ilmaz O.Y. et al. (2013). Boron in ferroalloy production, in Proceeding of the XIII INFACON. Almaty.

[22] Sheshukov O.Yu, Mikheenkov M.A., Nekrasov I.V. (2017). Utilization issues of refining slags for steelmaking: monograph, Nizhniy Tagil: NTI UrFU. 
[23] Ghose A., Chopra S., Young J.F. (1983). Microstructural characterization of doped dicalcium silicate polymorphs. J. Mater. Sci, vol. 18, pp. 2905-2914.

[24] Akberdin A.A., Zhuchkov V.I., Kim A.S. (2017). Stabilization of decayed metallurgical slugs. Proceedings of the congress with int. participation and conf. of young scientists "Fundamental research and applied development of the processes of processing and utilization of technogenic formations". Ekaterinburg: UB RAS.

[25] Grabeliks A.A., Demin B.L., Kairakbaev S.N. (2010). New technologies of crystalchemical stabilization of slag production for refined ferrochrome. Stal', no 5, pp. 7883. 